\title{
The Renal Handling of Parathyroid Hormone
}

\author{
ROLE OF PERITUBULAR UPTAKE AND GLOMERULAR FILTRATION
}

\author{
Kevin J. Martin, Keith A. Hruska, Jane Lewis, Charles Anderson, and \\ EdUARDO Slatopolsky, Renal Division, Department of Internal \\ Medicine, and Department of Surgery, Washington University School \\ of Medicine, St. Louis, Missouri 63110
}

A B S T RAC T The mechanisms of uptake of parathyroid hormone (PTH) by the kidney was studied in anesthetized dogs before and after ureteral ligation. During constant infusion of bovine PTH (b-PTH 1-84), the renal arteriovenous (A-V) difference for immunoreactive PTH (i-PTH) was $22 \pm 2 \%$. After ureteral ligation and no change in renal plasma flow, A-V i-PTH fell to $15 \pm 1 \%(P<0.01)$, indicating continued and significant uptake of i-PTH at peritubular sites and a lesser role of glomerular filtration (GF) in the renal uptake of i-PTH. Since, under normal conditions, minimal i-PTH appears in the final urine, the contribution of GF and subsequent tubular reabsorption was further examined in isolated perfused dog kidneys before and after inhibition of tubular reabsorption by potassium cyanide. Urinary i-PTH per $100 \mathrm{ml} \mathrm{GF}$ rose from $8 \pm 4 \mathrm{ng} / \mathrm{min}$ (control) to $170 \pm 45 \mathrm{ng} / \mathrm{min}$ after potassium cyanide. Thus, i-PTH is normally filtered and reabsorbed by the tubular cells. The physiological role of these two mechanisms of renal PTH uptake was examined by giving single injections of b-PTH 1-84 or synthetic b-PTH 1-34 in the presence of established ureteral ligation. After injection of b-PTH 1-84, renal A-V i-PTH was $20 \%$ only while biologically active intact PTH was present (15-20 min). No peritubular uptake of carboxyl terminal PTH fragments was demonstrable. In contrast, after injection of synthetic b-PTH 1-34, renal extraction of N-terminal i-PTH after ureteral ligation (which was $13.4 \pm 0.6 \%$ vs. $19.6 \pm 0.9 \%$ in controls) continued for as long as i-PTH persisted in the circulation. These studies indicate that both GF and peritubular uptake are important mechanisms for renal PTH uptake. Renal uptake of carboxyl terminal frag-

This work was presented, in part, at the American Federation of Clinical Research, Chicago, Ill., November 1976.

Dr. Martin is a recipient of a fellowship from the National Kidney Foundation.

Received for publication 28 January 1977 and in revised form 6 June 1977. ments of PTH is dependent exclusively upon GF and tubular reabsorption, whereas peritubular uptake can only be demonstrated for biologically active b-PTH 1-84 and synthetic b-PTH 1-34.

\section{INTRODUCTION}

Previous studies from this laboratory have shown that after a single injection of bovine parathyroid hormone (b-PTH $1-84)^{1}$ to dogs, the kidney extracted $20 \%$ of delivered carboxyl (COOH) terminal immunoreactivity, while the circulating species of immunoreactive parathyroid hormone (i-PTH) changed from intact hormone to a heterogeneous mixture of intact hormone and $\mathrm{COOH}$ terminal fragments, and finally to only $\mathrm{COOH}$ terminal fragments (1). In contrast, the liver demonstrated selective uptake of intact parathyroid hormone (PTH) and no demonstrable uptake of PTH fragments (2). These observations suggested that the mechanisms of uptake of i-PTH by liver and kidney are different; furthermore, the kidney possesses an uptake mechanism specific for the biologically inactive COOH-terminal fragments of PTH.

Studies in vitro have shown PTH activation of adenylate cyclase in membranes obtained from the peritubular side of the cell $(3,4)$. Since binding of labeled PTH to these membranes has been demonstrated $(3,5)$, it is possible that uptake of PTH by receptors on the peritubular membrane account for the renal extraction of i-PTH seen in our studies. On the other hand, PTH has a mol wt of 9,500 and therefore should be ultrafilterable at the level of the glomerulus. Autoradiographic evidence has shown labeled PTH in the proxi-

${ }^{1}$ Abbreviations used in this paper: A-V, arteriovenous; $\mathrm{COOH}$ terminal, carboxyl terminal; ICG, indocyanine green; $\mathrm{KCN}$, potassium cyanide; PAH, para-aminohippurate; PTH, parathyroid hormone; b-PTH 1-84, bovine PTH; i-PTH, immunoreactive PTH; syn-b-PTH 1-34, biologically active synthetic N-terminal fragment of bovine PTH. 
mal tubule (6), although minimal immunoreactive PTH appears in the final urine $(1,7)$.Thus, the possibility that glomerular filtration and subsequent reabsorption and degradation by the tubular cells also plays a role in the renal uptake of i-PTH must be considered. This type of mechanism has been described for other low molecular weight proteins such as lysozyme (8), insulin (9), and glucagon (10).

The present studies were designed to examine the relative roles of peritubular uptake and glomerular filtration in the renal handling of PTH in vivo.

\section{METHODS}

Preparation of dogs for studies in vivo. Studies were performed under pentobarbital anesthesia $(30 \mathrm{mg} / \mathrm{kg}$ ) on $12 \mathrm{mon}$ grel dogs weighing $18-25 \mathrm{~kg}$. Through a mid-line abdominal incision a polyethylene catheter was inserted into the left renal vein, and both ureters were catheterized. In two animals, a 25-gauge needle was placed in the left renal artery for infusion of indocyanine green. The catheters were brought out through stab wounds in the flanks and the incision closed. A femoral artery was catheterized for blood sampling and a jugular vein catheter was placed for infusion of solutions.

Study protocol. After priming doses of creatinine (50 $\mathrm{mg} / \mathrm{kg}$ ) and para-aminohippurate (PAH) $(4 \mathrm{mg} / \mathrm{kg}$ ) were given, a constant infusion of $0.9 \% \mathrm{NaCl}$ containing creatinine and PAH at $2.5 \mathrm{ml} / \mathrm{min}$ was begun, so as to maintain plasma concentrations of $9-10 \mathrm{mg} / 100 \mathrm{ml}$ and $1-2 \mathrm{mg} / 100$ $\mathrm{ml}$ for creatinine and PAH, respectively. Two groups of dogs were studied. The first group (five dogs) was given a constant infusion of purified b-PTH $1-84$ in $0.9 \% \mathrm{NaCl}$ containing $10 \%$ canine plasma at the rate of $150-200 \mathrm{ng} / \mathrm{min}$ with a Harvard syringe pump (Harvard Apparatus Co., Inc., Millis, Mass.). After a 90-min equilibration period, three control periods were obtained for creatinine clearance, renal plasma flow, and arteriovenous (A-V) difference across the kidney for creatinine and i-PTH. The left ureteral catheter was then clamped, and when the A-V creatinine difference across the kidney approached zero, three to six experimental periods were obtained to determine $\mathrm{A}-\mathrm{V}$ difference for i-PTH across the kidney. Renal plasma flow during ureteral obstruction was measured by electromagnetic flowmeter (three dogs) or by dye dilution techniques (two dogs) with an infusion of indocyanine green (ICG) (Hyson, Westcott, and Dunning, Inc., Baltimore, Md.) into the renal artery.

The second group of seven dogs received a single injection $(5 \mu \mathrm{g} / \mathrm{kg}$ ) of b-PTH $1-84$ (three dogs), or synthetic b-PTH (syn-b-PTH 1-34) (four dogs) in the presence of established ureteral obstruction ( $\mathrm{A}-\mathrm{V}$ creatinine difference less than 5\%). Blood samples for A-V difference of i-PTH across the kidney were obtained at intervals of 2-5 min for 60-90 min after injection of PTH.

Studies on isolated perfused kidneys. Kidneys from mongrel dogs were perfused with fresh heparinized autologous blood diluted $4: 1$ with $0.9 \% \mathrm{NaCl}$ at $37^{\circ} \mathrm{C}$ on a Waters MOX 100 kidney perfusion apparatus (Waters Instruments Inc., Rochester, Minn.) as previously described (11). Purified b-PTH 1-84 was infused into the perfusion circuit at $200 \mathrm{ng} / \mathrm{min}$. Urinary losses of fluid and electrolytes were replaced with $0.45 \% \mathrm{NaCl}$ containing creatinine and $\mathrm{PAH}$ to maintain their concentrations in the perfusate. After three control periods, potassium cyanide (KCN) was added to the perfusate to a final concentration of $3 \mathrm{mM}$ and further clearance periods collected.
Studies in the rat. To examine the relative roles of renal plasma flow and glomerular filtration on PTH uptake in a second species, female Holtzman rats weighing $300-350 \mathrm{~g}$ were studied under pentobarbital anesthesia (50 $\mathrm{mg} / \mathrm{kg}$ i.p.) $60 \mathrm{~min}$ after bilateral ureteral ligation (five rats); bilateral nephrectomy (four rats); or sham operation (four rats). A single injection of syn-b-PTH 1-34 $(10 \mu \mathrm{g} / 100 \mathrm{~g}$ body wt) was administered through a jugular vein catheter and blood samples drawn from a carotid artery cannula at 3,20 , 40 , and $60 \mathrm{~min}$ after injection. Blood volume was replaced by administering an equal volume of $0.9 \% \mathrm{NaCl}$.

Source of PTH. Highly purified b-PTH 1-84 was obtained from Inolex Corp., Biomedical Div., Glenwood, Ill. (sp act $900-1,500 \mathrm{u} / \mathrm{mg}$ in a rat bioassay). syn-b-PTH 1-34 was obtained from Beckman Instruments, Inc., Spinco Div., Palo Alto, Calif. (sp act $3,700 \mathrm{U} / \mathrm{mg}$ in a renal adenylate cyclase system).

Chemical determinations. Creatinine was measured by the Jaffe reaction as described by Folin (12) and adapted for the Technicon AutoAnalyzer (Technicon Instruments Corp., Tarrytown, N. Y.). PAH was measured by the method of Harvey and Brothers (13) as adapted for the Technicon AutoAnalyzer. ICG was measured as described previously (2).

Radioimmunoassay methods. Plasma levels of i-PTH after injection of b-PTH 1-84 and syn-b-PTH 1-34 were measured as described previously $(1,2)$. In the present studies antiserum $\mathrm{CH} 9$, which reacts primarily with carboxyl determinants (1), was used in a final dilution of $1: 80,000$ and antiserum CH9N, which is specific for the synthetic amino terminal fragment of b-PTH (1), was used in a final dilution of $1: 25,000$. Endogenous canine PTH was subtracted as a background from all samples (normal range $0.1-0.45 \mathrm{ng}$ b-PTH eq $/ \mathrm{ml}$ ).

For assay of i-PTH in the urine obtained from the isolated perfused kidneys, appropriate controls for nonspecific binding, tracer binding, and standard curves were performed with urine from a control isolated, perfused kidney at volumes identical to the unknown urine assayed for i-PTH. Effects of KCN on the assay system were likewise evaluated. The effect of these additions on the radioimmunoassay was insignificant.

Calculations. Renal plasma flow (PTH) was calculated with the Wolff modification of the Fick principle (14). Renal plasma flow with ICG was determined by dividing the infusion rate of ICG by the difference between the ICG concentration in renal vein and aorta. Extraction of creatinine or i-PTH by the kidney was determined by the $\mathrm{A}-\mathrm{V}$ difference across the kidney divided by the arterial creatinine or i-PTH concentration. Statistical analysis of paired or nonpaired data was performed with the Student's $t$ test.

\section{RESULTS}

Studies during constant infusion of b-PTH 1-84 are shown in Table I and Fig. I. Renal plasma flow averaged $138 \pm 18 \mathrm{ml} / \mathrm{min}$ in the control periods and $143 \pm 24 \mathrm{ml} / \mathrm{min}$ after ureteral obstruction. These values are not significantly different from each other. Creatinine extraction by the kidney decreased from $20 \pm 2 \%$ to $4 \pm 1 \%$ after ureteral obstruction. On the other hand, mean extraction for i-PTH fell from 22 $\pm 2 \%$ in control to $15 \pm 1 \%$ in the experimental periods $(P<0.01)$. Thus, the kidney continues to extract i-PTH from the circulation when the glomerular 
TABLE I

Effect of Ureteral Obstruction on Renal Extraction of i-PTH during Constant Infusion of b-PTH 1-84

\begin{tabular}{|c|c|c|c|c|c|c|c|c|}
\hline \multirow[b]{2}{*}{ Dog no. } & \multicolumn{2}{|c|}{$\begin{array}{c}\text { Left } \\
\text { kidney } \\
\mathbf{C}_{\mathrm{CR}} \\
\end{array}$} & \multicolumn{2}{|c|}{ RPF } & \multicolumn{2}{|c|}{$\begin{array}{l}\text { Creati- } \\
\text { nine } \\
\text { extr. }\end{array}$} & \multicolumn{2}{|c|}{$\begin{array}{l}\text { i-PTH } \\
\text { extr. }\end{array}$} \\
\hline & C & $\mathbf{E}$ & C & E & C & $\mathbf{E}$ & C & $\mathbf{E}$ \\
\hline & \multicolumn{2}{|c|}{$\mathrm{mllmin}$} & \multicolumn{2}{|c|}{$\mathrm{ml} / \mathrm{min}$} & \multicolumn{2}{|c|}{$\%$} & \multicolumn{2}{|c|}{$\%$} \\
\hline 1 & 27 & - & 120 & 147 & 26 & 6 & 28 & 17 \\
\hline 2 & 18 & - & 89 & 75 & 17 & 4 & 26 & 17 \\
\hline 3 & 23 & - & 160 & 210 & 19 & 3 & 15 & 12 \\
\hline 4 & 31 & - & 125 & 110 & 22 & 5 & 19 & 11 \\
\hline 5 & 27 & - & 196 & 174 & 18 & 3 & 22 & 16 \\
\hline Mean & 25 & - & 138 & 143 & 20 & 4 & 22 & 15 \\
\hline SEM & 4 & - & 18 & 24 & & 1 & 2 & 1 \\
\hline$P$ & & & & & & & & 01 \\
\hline
\end{tabular}

$\mathrm{C}_{\mathrm{CR}}$, exogenous creatinine clearance; $\mathrm{RPF}$, renal plasma flow; creatinine extr., arteriovenous creatinine difference divided by arterial creatinine concentration $\times 100$; i-PTH extr., percent extraction of immunoreactive PTH. C = control; $\mathrm{E}=$ experimental. Statistical analysis by paired $t$ test.

filtration rate is decreased by ureteral obstruction during constant infusion of b-PTH 1-84. However, the reduction in the A-V difference for i-PTH after ureteral obstruction compared to control presumably indicates that a fraction of the renal i-PTH uptake is due to glomerular filtration.

Studies in the isolated perfused kidney. To further examine the role of glomerular filtration and tubular reabsorption in the renal removal of i-PTH from the circulation, studies were performed in isolated perfused dog kidneys, before and after inhibition of
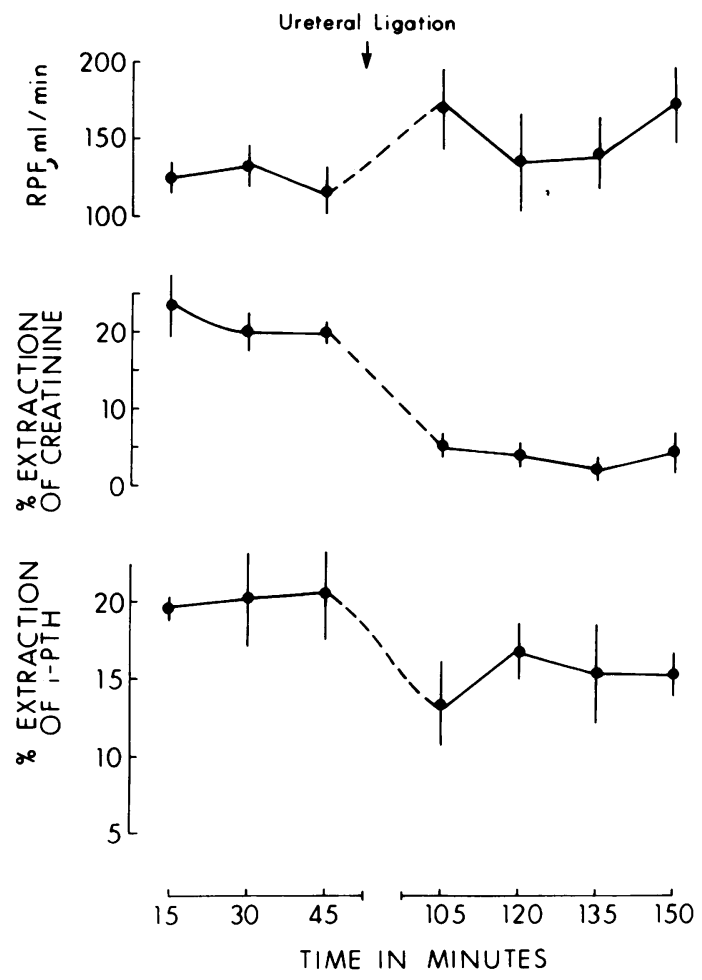

FigURE 1 Effect of ureteral obstruction on renal extraction of i-PTH during constant infusion of b-PTH 1-84. Results are shown as mean $\pm S E M$ for five dogs. RPF, renal plasma flow.

tubular reabsorption by the addition of $3 \mathrm{mM} \mathrm{KCN}$ to the perfusate. The results of three such experiments are shown in Table II and Fig. 2. KCN decreased creatinine clearance from $28.2 \pm 3.8 \mathrm{ml} / \mathrm{min}$ to 10.5

TABLE II

Effect of KCN on Urinary Excretion of i-PTH in the Isolated Perfused Dog Kidney

\begin{tabular}{|c|c|c|c|c|c|c|c|c|c|c|}
\hline \multirow{2}{*}{$\begin{array}{c}\text { Expt. } \\
\text { no. }\end{array}$} & \multicolumn{2}{|c|}{$\mathrm{C}_{\mathrm{CR}}$} & \multicolumn{2}{|c|}{ Arterial i-PTH } & \multicolumn{2}{|c|}{$\mathrm{U}_{\mathrm{i}-\mathrm{PTH}} \cdot \mathrm{V}$} & \multicolumn{2}{|c|}{$\frac{\mathrm{C}_{\mathrm{Na}}}{\mathrm{C}_{\mathrm{CR}}} \times 100$} & \multicolumn{2}{|c|}{$\frac{\mathrm{U}_{1-\mathrm{PTH}} \cdot \mathrm{V}}{\mathrm{C}_{\mathrm{CR}}} \times 100$} \\
\hline & $\mathrm{C}$ & $\mathbf{E}$ & C & $\mathbf{E}$ & C & $\mathbf{E}$ & C & $\mathbf{E}$ & C & $\mathbf{E}$ \\
\hline & \multicolumn{2}{|c|}{$\mathrm{ml} / \mathrm{min}$} & \multicolumn{2}{|c|}{$n g / m l$} & \multicolumn{2}{|c|}{$n g / m i n$} & & & \multicolumn{2}{|c|}{$n g / m i n$} \\
\hline 1 & 35.0 & 8.1 & 9.6 & 12.9 & 0.6 & 10.4 & 0.4 & 52.1 & 1.6 & 128.4 \\
\hline 2 & 22.0 & 10.2 & 4.9 & 5.3 & 3.3 & 14.3 & 2.1 & 65.0 & 15.0 & 259.8 \\
\hline 3 & 27.5 & 13.1 & 5.6 & 6.6 & 2.5 & 15.6 & 1.2 & 32.2 & 5.8 & 122.1 \\
\hline Mean & 28.2 & 10.5 & 6.7 & 8.3 & 2.1 & 13.4 & 1.2 & 49.7 & 7.5 & 170.1 \\
\hline SEM & 3.8 & 1.5 & 1.5 & 2.4 & 0.8 & 1.6 & 0.5 & 9.6 & 3.9 & 44.8 \\
\hline
\end{tabular}

$\mathrm{C}_{\mathrm{CR}}$, exogenous creatinine clearance; arterial i-PTH, arterial immunoreactive PTH concentration; $\mathrm{U}_{\mathrm{i}-\mathrm{PTH}} \cdot \mathrm{V}$, urine flow rate multiplied by urinary i-PTH concentration: $\frac{\mathrm{C}_{\mathrm{Na}}}{\mathrm{C}_{\mathrm{CR}}} \times 100$, clearance of sodium divided by clearance of creatinine $\times 100 ; \frac{U_{i-P T H} \cdot V}{C_{C R}} \times 100$, urinary excretion of i-PTH per $100 \mathrm{ml}$ glomerular filtration rate. $\mathrm{C}=$ Control; $\mathrm{E}=$ experimental. 


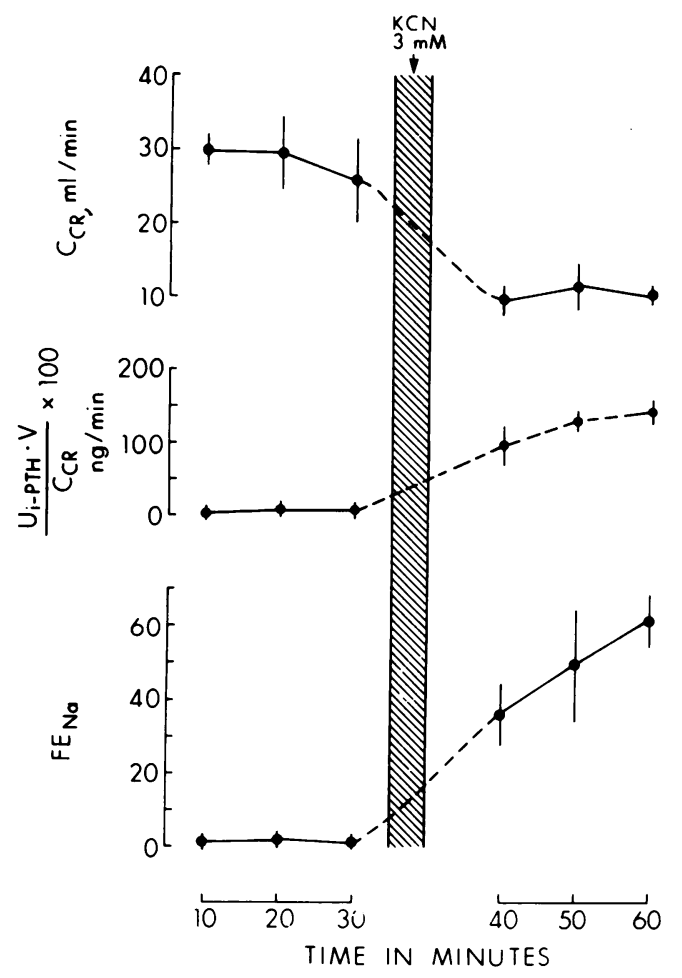

FIGURE 2 Effect of KCN on the urinary excretion of i-PTH in the isolated perfused dog kidney. Results are shown as mean $\pm S E M$ for three experiments. $C_{C R}$, exogenous creatinine clearance.

$\pm 1.5 \mathrm{ml} / \mathrm{min}$. Fractional sodium excretion increased from $1.2 \pm 0.5 \%$ to $49.7 \pm 9.6 \%$. Urinary excretion of i-PTH, expressed per 100 milliliters of glomerular filtration rate, increased from $7.5 \pm 3.9 \mathrm{ng} / \mathrm{min}$ to 170 $\pm 45 \mathrm{ng} / \mathrm{min}$, suggesting that i-PTH under normal conditions is indeed filtered and reabsorbed by the tubular cells.

Studies with a single injection of b-PTH 1-84 or syn-b-PTH 1-34. To ascertain the physiological significance of the two mechanisms for renal uptake of i-PTH, i.e., (a) peritubular uptake and (b) glomerular filtration and tubular reabsorption, studies were performed after a single injection of b-PTH 1-84 (three dogs) and syn-b-PTH 1-34 (four dogs), in the presence of established ureteral obstruction when A-V creatinine difference was markedly reduced. The pattern of renal extraction of immunoreactivity after injection of b-PTH 1-84 (assayed with antiserum CH9) is shown in Fig. 3. Extraction of i-PTH after injection of b-PTH $1-84$ was $20 \pm 2 \%$ for 15 min after injection and then fell to zero. No further extraction was seen up to $60 \mathrm{~min}$ after injection, in spite of persisting high levels of i-PTH in the circulation $(2-5 \mathrm{ng} / \mathrm{ml})$.

In contrast, after a single injection of the biologi-

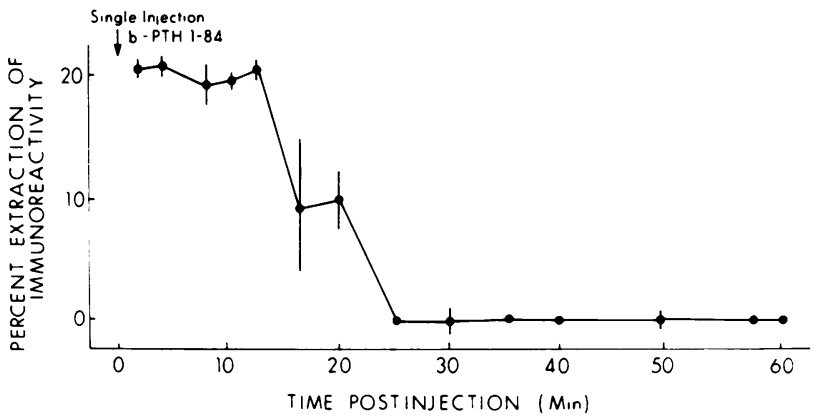

FIGURE 3 Renal extraction of i-PTH after a single injection of b-PTH 1-84 in the presence of established ureteral obstruction. Results are shown as mean \pm SEM for three dogs.

cally active synthetic $\mathrm{N}$-terminal fragment of bovine PTH (syn-b-PTH 1-34), extraction by the obstructed kidney was constant (mean $13.4 \pm 0.06 \%$ ) until immunoreactively disappeared from the circulation $(90 \mathrm{~min}$ postinjection). These studies are portrayed in Fig. 4 compared with the extraction of immunoreactivity by the normal kidney (mean $19.6 \pm 0.9 \%$ ). PTH extraction by the obstructed kidney was significantly reduced compared with the normal kidney $(P<0.001)$, presumably indicating the contribution of glomerular filtration to the renal uptake of this PTH fragment.

Studies in the rat. The studies on the effect of ureteral obstruction on the renal uptake of syn-b-PTH 1-34 were extended to another species, the rat, and compared with the effect of bilateral nephrectomy. The disappearance of $\mathrm{N}$-terminal immunoreactivity from plasma was studied in three groups of rats after a single injection of syn-b-PTH 1-34 given $1 \mathrm{~h}$ after bilateral ureteral ligation, bilateral nephrectomy, or sham operation (Fig. 5). Radioimmunoassay utilized antiserum CH9N (see Methods). Disappearance of

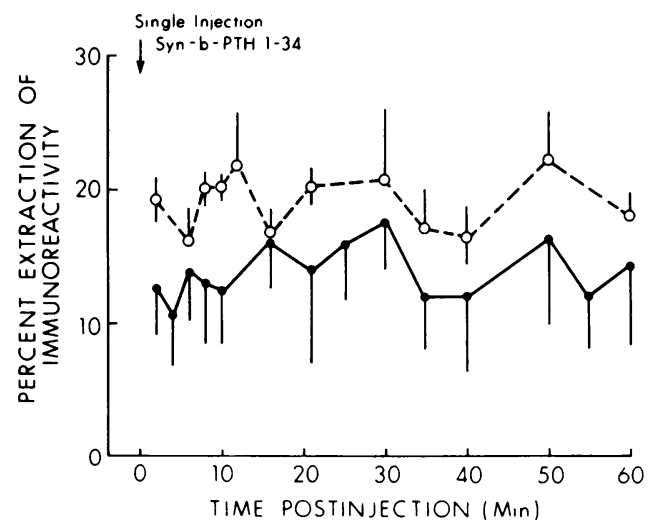

FIGURE 4 Renal extraction of N-terminal immunoreactivity after a single injection of syn-b-PTH 1-34 by normal kidneys $(\mathrm{O}---\mathrm{O})$ and in the presence of established ureteral obstruction (- Results shown are the mean \pm SEM for four dogs in each group. 


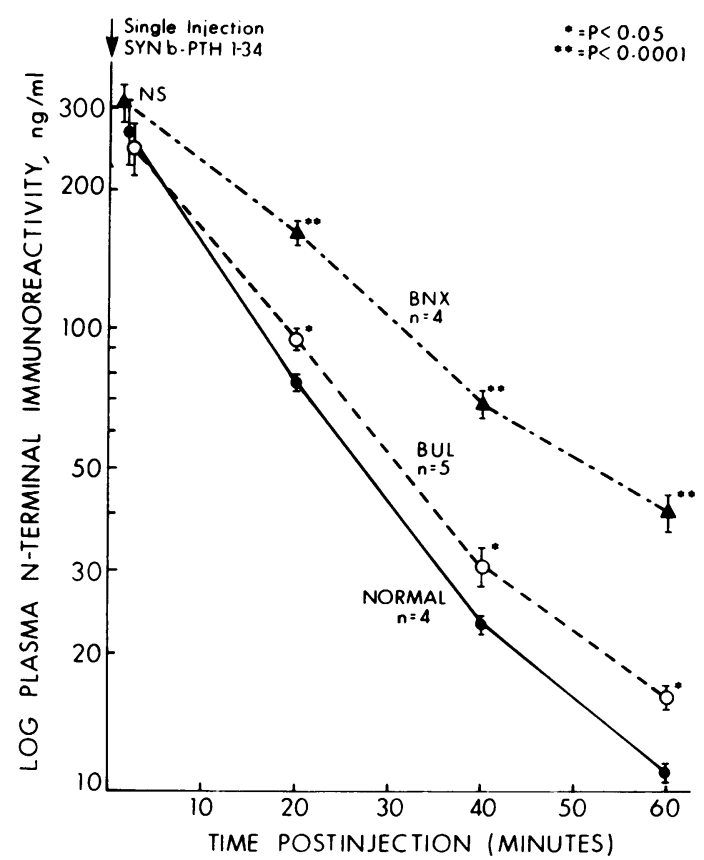

FIGURE 5 Effect of bilateral ureteral ligation (BUL) and bilateral nephrectomy (BNX) on the plasma disappearance of immunoreactivity after a single injection of syn-b-PTH 1-34 in the rat. Each point represents the mean arterial i-PTH concentration \pm SEM.

immunoreactivity was slightly, although significantly delayed in the bilateral ureteral ligation group $(P$ $<0.05$ ), indicating the role of glomerular filtration on the renal uptake of syn-b-PTH 1-34. The bilaterally nephrectomized group, however, demonstrated marked delay in the disappearance of immunoreactivity $(P<0.001)$ compared with the sham (normal) or bilateral ureteral ligation groups, indicating the importance of peritubular uptake in the clearance of this biologically active synthetic N-terminal fragment of bovine PTH.

\section{DISCUSSION}

Previous studies from this laboratory have demonstrated the importance of the kidney in the removal of immunoreactive PTH from the circulation (1). Additional studies of the uptake of PTH by the liver demonstrated selective uptake of the intact hormone and no uptake of PTH fragments by this organ (2), whereas the kidney could extract all immunoreactive species of PTH. Uptake of the (biologically inactive) carboxyl terminal fragments of PTH by the kidney suggested that there may be more than a single mechanism of uptake of i-PTH by this organ. The present studies were designed to evaluate the roles of peritubular uptake and glomerular filtration in the uptake of immunoreactive PTH by the kidney.
The principle technique used in these studies employed ureteral obstruction to reduce glomerular filtration and preserve renal plasma flow. Although low values of glomerular filtration may persist in the presence of ureteral obstruction in this model, and as much as $25 \%$ of filtered creatinine may be reabsorbed under conditions of increased intratubular pressure (15), the marked reduction in creatinine extraction from $20 \pm 2 \%$ in control to $4 \pm 1 \%$ after ureteral obstruction indicates a substantial reduction in glomerular filtration rate.

The initial studies, Table I and Fig. 1, performed during a constant infusion of b-PTH 1-84, examined the A-V difference of i-PTH across the kidney before and after ureteral obstruction. Renal extraction of i-PTH decreased from $22.0 \pm 2 \%$ in the control periods to $15.0 \pm 1 \%$ after ureteral obstruction. These results demonstrate that although the reduction in glomerular filtration rate caused by ureteral obstruction is associated with a fall in the renal extraction of i-PTH, significant extraction of i-PTH persists which presumably relates at least in part to uptake of i-PTH at peritubular sites.

Previous studies have shown that only small amounts of immunoreactive PTH appear in the final urine under normal conditions $(1,7)$. However, the possibility that PTH is filtered and subsequently reabsorbed by the tubular cells remains a possibility. This possible mechanism of renal PTH uptake was examined in the isolated perfused dog kidney after inhibition of tubular reabsorption with $\mathrm{KCN}$ as previously described in studies designed to examine the renal handling of lysozyme (8). After inhibition of tubular reabsorption, absolute urinary excretion of i-PTH increased more than sixfold (Table II and Fig. 2), indicating that i-PTH is being filtered at the glomerulus and is reabsorbed by the tubular cells under normal conditions. The increase in urinary excretion of i-PTH after inhibition of tubular reabsorption is of even greater magnitude (20-fold) if the decrease in creatinine clearance after the addition of $\mathrm{KCN}$ is considered. True fractional excretion of i-PTH was not calculated since preliminary studies in our laboratory indicate that approximately $30 \%$ of intact PTH is bound to plasma proteins (unpublished results) and therefore may not all be ultrafilterable at the level of the glomerulus. Furthermore, it is not known if the immunoreactive fragments of PTH share the same protein binding characteristics as intact hormone. In addition, because of the immunoheterogeneity of circulating PTH both in the intact animal $(1,2)$ and in the isolated perfused kidney $(11)$, it is unlikely that the different immunoreactive fragments of PTH of different molecular weights would have the same seiving coefficients. Thus, the calcula- 
tions of true ultrafilterable i-PTH is not possible at the present time.

The use of single injections of b-PTH 1-84 in the presence of established ureteral obstruction (Fig. 3) provided a means of evaluating the peritubular uptake of i-PTH as the circulating species of i-PTH changed from predominantly intact hormone to a heterogeneous mixture of intact hormone and its fragments and finally to $\mathrm{COOH}$ terminal fragments alone $(1,2)$. We have shown previously that intact PTH is rapidly cleared from the circulation after single injection of b-PTH 1-84 and that 15-25 min after injection circulating i-PTH consists only of $\mathrm{COOH}$ terminal fragments (2). The results of such studies in three animals (Fig. 3) show that the obstructed kidney extracts i-PTH for 15-20 min after a single injection of b-PTH 1-84, and no further extraction could be demonstrated during the next $90 \mathrm{~min}$ in spite of persisting high levels of i-PTH in the circulation $(2-5 \mathrm{ng} / \mathrm{ml})$. These studies show that renal extraction of i-PTH by the obstructed kidney only occurs when biologically active intact hormone is present in the circulation. Thus, after a single injection of b-PTH 1-84 the nonfiltering kidney appears to demonstrate selective uptake of intact PTH and no uptake of the biologically inactive C-terminal i-PTH fragments. This selective uptake of intact hormone is similar to PTH uptake by the liver seen in our previous studies (2). However, after single injection of the biologically active synthetic N-terminal fragment of b-PTH (syn b-PTH 1-34) in the presence of established ureteral obstruction (Fig. 4), the obstructed kidney continued to extract N-terminal immunoreactivity after a single injection of syn b-PTH 1-34 until immunoreactivity disappeared from the circulation. The mean extraction by the obstructed kidney $(13.4 \pm 0.6 \%)$ was less than that of normal kidneys $(19.6 \pm 0.9 \%)$ and can be attributed to the contribution of glomerular filtration to the renal extraction of $\mathrm{N}$ terminal immunoreactivity under normal conditions. The continued extraction of $\mathrm{N}$-terminal immunoreactivity by the obstructed kidney is presumably related to uptake of this biologically active PTH fragment at peritubular sites. This observation suggests that the receptors of the kidney differ from those in the liver, since no hepatic uptake of syn-b-PTH 1-34 was demonstrable in our previous studies (2).

The relative roles of peritubular uptake and glomerular filtration in the renal uptake of biologically active PTH were evaluated in the rat by comparing the disappearance of $\mathrm{N}$-terminal immunoreactivity in normal rats, in rats after bilateral ureteral ligation and in bilaterally nephrectomized rats, after a single injection of syn b-PTH 1-34 (Fig. 5). Plasma disappearance of i-PTH was somewhat delayed in the bilateral ureteral ligation group $(P<0.05)$, but was

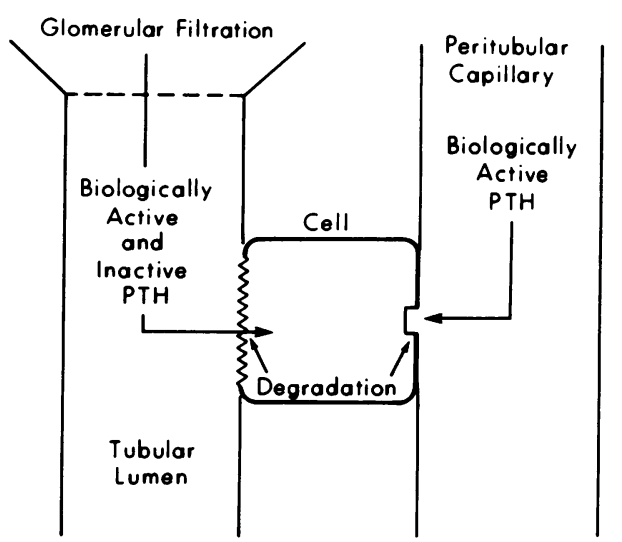

FIGURE 6 Schematic representation of the renal mechanisms of PTH uptake.

markedly prolonged in the bilaterally nephrectomized group $(P<0.001)$, indicating the major role of peritubular uptake of this biologically active fragment of PTH.

Thus, the present studies demonstrate that two mechanisms exist for the renal removal of i-PTH from the circulation (Fig. 6). Uptake of biologically inactive PTH fragments appears to be dependent upon glomerular filtration and reabsorption and degradation by the tubular cells. On the other hand, peritubular uptake can only be demonstrated for the biologically active intact hormone and its biologically active synthetic $\mathrm{N}$-terminal fragment. The present results differ from recent studies on the renal handling of ${ }^{125} \mathrm{I}-\mathrm{b}-\mathrm{PTH}$ by the kidney. In these preliminary studies glomerular filtration and tubular reabsorption was felt to be the principle renal mechanism for PTH uptake (16). However, these studies may be reconciled with the present results in view of the fact that PTH iodinated by the chloramine-T method is biologically inactive and does not bind specifically to renal cortical membranes in vitro (17). Thus, the renal uptake of the biologically inactive ${ }^{125} \mathrm{I}-\mathrm{b}-\mathrm{PTH}$ may be analogous to the renal uptake of the biologically inactive PTH fragments seen in the present studies. That two mechanisms, i.e., peritubular uptake and glomerular filtration, are responsible for the renal uptake of PTH is not unique to this peptide and has previously been described for insulin, proinsulin and C-peptide (9), gastrin (18), and glucagon (10). The demonstration that the renal uptake of the biologically inactive fragments of i-PTH is dependent upon glomerular filtration, while the biologically active forms of i-PTH (intact b-PTH 1-84 and syn b-PTH 1-34) are handled mainly by peritubular uptake, could explain the marked accumulation of biologically inactive PTH fragments in patients with renal failure. 


\section{ACKNOWLEDGMENTS}

The authors thank Dr. Saulo Klahr for his critical review of this manuscript and Mrs. Patricia Verplancke for her secretarial assistance.

This investigation was supported by U. S. Public Health Service grants AM-05248, AM-09976, and AM-07126 from the National Institute of Arthritis, Metabolism, and Digestive Diseases.

\section{REFERENCES}

1. Hruska, K. A., R. Kopelman, W. E. Rutherford, S. Klahr, and E. Slatopolsky. 1975. Metabolism of immunoreactive parathyroid hormone in the dog. The role of the kidney and the effects of chronic renal disease. J. Clin. Invest. 56: 39-58.

2. Martin, K., K. Hruska, A. Greenwalt, S. Klahr, and E. Slatopolsky. 1976. Selective uptake of intact parathyroid hormone by the liver. Differences between hepatic and renal uptake. J. Clin. Invest. 58: 781-788.

3. DiBella, F. P., T. P. Dousa, S. S. Miller, and C. D. Arnaud. 1974. Parathyroid hormone receptors of renal cortex: Specific binding of biologically active ${ }^{125} \mathrm{I}$ labelled hormone and relationship to adenylate cyclase activation. Proc. Natl. Acad. Sci. U. S. A. 71: 723-726.

4. Chu, L. L. H., L. R. Forte, C. S. Anast, and D. V. Cohn. 1975. Interaction of parathyroid hormone with membranes of kidney cortex: Degradation of the hormone and activation of adenylate cyclase. Endocrinology. 97: 1014-1023.

5. Malbon, C. C., and J. E. Zull. 1974. Interactions of parathyroid hormone and plasma membranes from rat kidney. Biochem. Biophys. Res. Commun. 56: 952-958.

6. Nordquist, R. E., and G. M. A. Palmieri. 1974. Intracellular localization of parathyroid hormone in the kidney. Endocrinology. 95: 229-237.

7. Singer, F. R., G. V. Segre, J. F. Habener, and J. T. Potts, Jr. 1975. Peripheral metabolism of bovine para- thyroid hormone in the dog. Metab. Clin. Exp. 24: 139-144.

8. Maack, T. 1975. Renal handling of low molecular weight proteins. Am. J. Med. 58: 57-64.

9. Katz, A. I., and A. H. Rubenstein. 1973. Metabolism of proinsulin, insulin, and C-peptide in the rat. J. Clin. Invest. 52: 1113-1121.

10. Emmanuel, D. S., J. B. Jaspan, S. F. Kuku, A. H. Rubenstein, and A. I. Katz. 1976. Pathogenesis and characterization of hyperglucogonemia in the uremic rat. J. Clin. Invest. 58: 1266-1272.

11. Hruska, K. A., K. Martin, A. Greenwalt, C. Anderson, S. Klahr, and E. Slatopolsky. 1977. Metabolism of parathyroid hormone by the isolated perfused dog kidney. Role of glomerular filtration rate and perfusate $\mathrm{Ca}^{++}$ concentrations. J. Clin. Invest. 60: 501-510.

12. Hawk, P. B., B. L. Oser, and W. H. Summerson. 1947. Practical Physiological Chemistry. The Blakiston Co., Div. of McGraw-Hill Book Company, New York. 12th edition. 506.

13. Harvey, R. B., and A. J. Brothers. 1962. Renal extraction of para-amino-hippurate and creatinine measured by continuous in vivo sampling of arterial and renal-vein blood. Ann. N. Y. Acad. Sci. 102: 46-54.

14. Wolff, A. W. 1950. The urinary function of the kidney. Grune \& Stratton, Inc., Div. of Academic Press, Inc., New York. 65.

15. Lorentz, W. B., W. E. Lassiter, and C. W. Gottschalk. 1972. Renal tubular permeability during increased intrarenal pressure. J. Clin. Invest. 51: 484-492.

16. Kau, S. T., and T. Maack. 1976. Handling of parathyroid hormone (125I-b-PTH) by the rat kidney. Proc. Am. Soc. Nephrol. 102A. (Abstr.)

17. Sutcliffe, H. S., T. J. Martin, J. A. Eisman, and R. Pilczyk. 1973. Binding of parathyroid hormone to bovine kidney cortex plasma membranes. Biochem. J. 134: 913-921.

18. Grace, S. G., W. D. Davidson, and D. State. 1974. Renal mechanisms for removal of gastrin from the circulation. Surg. Forum. 25: 323-325. 